Annual Report of the Government Ophthalmic Hospital, Madras,

1935. Price, 10 annas.

The annual report of the Government Ophthalmic Hospital, Madras, follows the customary lines and contains a mass of statistics, together with some financial details. Section 4 shows the classes of diseases treated both in- and out-patients. Conjunctivitis accounts for a large amount and we note that during the year 157 cases of trachoma were treated as in-patients and 1,337 as out-patients. The incidence of cataract is very heavy : 2,223 cases of senile cataract were treated as in-patients and 3,124 as out-patients. The report also gives details of the training of medical students and post-graduate work. The surgical operations are set out in tabular form.

\title{
CORRESPONDENCE
}

To the Editors of THE BRITISH JouRnal OF OpHTHALMOLOGy.

SIRS,-Mr. H. B. Stallard, in his article on "Katholysis in the Treatment of Retinal Detachment" published in your issue of January, 1937, states that certain serious complications, viz., cyclitis, iritis, cataract and optic neuritis may follow the treatment of retinal detachment by surgical diathermy. This statement is not in accordance with my own experience, indeed, I have never encountered one of these complications in connection with any case which I have treated by this method. Also, with regard to the localization of the retinal hole in relation to the external surface of the sclera, I have found that this can be accurately done in most cases by means of diathermy.

Yours faithfully,

LONDON,

R. AfFleck GReEves.

January 25, 1937.

To the Editors of THE BRITISH JoURNAL OF OPHTHALMOLOGY.

SIRS,- - I am interested in Mr. Greeves' letter and his comments to the effect that he has never encountered cyclitis, iritis, cataract and optic neuritis after surgical diathermy in the treatment of retinal detachment. In the Brit. Jl. of Ophthal., Vol. XVII, p. 294, 1933, I reported the histological appearances of an eye successfully treated for retinal detachment by surgical diathermy at St. Thomas's Hospital. The patient died from pulmonary thrombosis 19 days after operation. The operated eye was treated with surface 
diathermy in the upper temporal quadrant between the ora serrata and the equator.

The specimen showed iridocyclitis, proliferation of the nonpigmented layer of the ciliary epithelium and many fibroblasts in the circumlental space.

Arruga in his recent textbook, "Detachment of the Retina," in describing the complications after surgical diathermy makes the following statement. "Another complication is the development of a cataract. This occurs in eyes severely traumatised by the treatment, but is rare with modern technique. When the lens opacity appears late (several months after operation), in patients of advanced age, it may be a senile cataract, developing prematurely as a result of the ocular disorders following the detachment of the retina or its treatment."

In the literature of retinal detachment other authors mention cyclitis, iritis, cataract and optic neuritis as complications.

However, I have not seen optic neuritis as a complication in my own series of cases, but I have formed the impression that some cases which had been treated unsuccessfully by diathermy developed lens opacities and a mild iridocyclitis earlier than would have been the case in the ordinary course of events. It is of course well-known that these complications may be remote sequelae to retinal detachment but it seemed to me that possibly surgical diathermy had hastened their onset in some cases.

I agree with $\mathrm{Mr}$. Greeves that localization may be accurately done by means of surface diathermy, but I have found it on the whole less consistent and precise than katholysis.

Yours faithfully,

H. B. Stallard.

LONDON,

January 26, 1937.

\section{"RETICULAR SUPERFICIAL VACUOLATION" OF THE CORNEA}

To the Editors of The British Journal of Ophthalmology.

SIRS,-May I ask if you can grant the space for the following comment :- Under the title "Reticular Superficial Vacuolation" I recently gave a brief description* of a definite clinical condition of the cornea, not, as far as I am aware, hitherto described. The necessary compression of space involved abbreviation which, as I now see, has led to an unsatisfactory presentation of the subject. Although, in describing this in a general text-book, I have classed it

" "The Eye and its Diseases," edited by Berens (Saunders \& Co., 1936). 